\section{HANDBOOK OF POISONS}

By Robert H. Dreisbach, M.D., Ph.D. Pp. 426. Los Altos: Lange Medical Publications. 1956. $\$ 3.00$.

Only in format can this be considered a handbook, for within its modest compass lies more practical information about poisons and poisoning than can be found in most textbooks. One wonders at the omniscience of the author that has enabled every worthwhile detail of nearly every known poison (whether medicinal, agricultural or industrial) to be included. Most poisoning cases demand speedy diagnosis and treatment and a work of reference should be designed with this essential in mind; in the present volume the text is so displayed that no time will be lost in finding what immediate measures should be taken. The structural formula of the poison is first given, followed by the clinical findings, treatment, prophylaxis and prognosis. Each of these sub-headings contains just the information one needs and, perhaps, with the dogmatism so comforting in an emergency!

It is natural to turn to those pages dealing with poisons with which we are most often concerned and, in doing so, it is at once apparent how divergent views on treatment may be. In barbiturate coma the author holds no brief for the analeptic drugs and states that no antidote is known; no mention is made of the antipodean antidote bemegride (" Megimide'), which has been used with considerable success. Indeed, what does or does not constitute an antidote may have given the author some trouble; under ' anticoagulants' neither heparin nor the synthetics are accorded one, whereas I per cent. injection of protamine sulphate surely fills the bill for the former and natural vitamin $K_{1}$ for the latter. This monograph on anticoagulants is not quite satisfactory; the author fails to stress the importance of using vitamin $K_{1}$ and not one of the synthetic analogues which have been used in the past with such poor results. No mention at all is made of protamine sulphate, which removes circulating heparin.

But if it is the reviewer's job to find faults in a work, then this one has presented a difficult task. It is easier (and pleasurable) in this instance to give unqualified approval to a volume to which every casualty department certainly, and perhaps every general practitioner, ought to have ready access.

M.H.P.

\section{A FOLLOW-UP STUDY OF WAR NEUROSES V.A. Medical Monograph}

By Norman Q. Brill, M.A., and Gilbert W. Berbe, Ph.D. Pp. xviii +393 , with I I diagrams. Washington: Veterans Administration. 1955.

As the authors say in their introduction, comparatively little is known about the natural history of the neuroses. This book is the report of a follow-up study of neuroses occurring in time of war among the United States Forces; the study was directed by the National Research Council and financed by the Veterans Administration. The material for the study consisted of a representative sample of men admitted to the Forces in 19440 985 from the Army and 490 from the Navy ana Marine Corps. Of this total of 1,475 men, 955 were examined by one of 225 psychiatrists through out the country, and the rest studied on the basis of records only. Most of the psychiatric examin tions were made in the fifth or sixth year after fir admission for psychoneurosis. Information in the examination and reports was converted into a forif allowing of coding and statistical analysis.

The bulk of the book is made up of a detaile'd survey of this analysis, and it does not lend itse to summarizing. A vast amount of information is contained in the many tables and chapters, and the book is well and clearly set out. Part I is concerneeP with characteristics of the population sampled Part II with an analysis of follow-up data, Part IE with an analysis of military experience, Part IDळ with a survey of the pre-service period, and Part with the implications of this study for the utilization of manpower.

Perhaps the most interesting part of the book for the clinical worker is Chapter IV, on follow-ud status. Ninety per cent. of the men examined complained of symptoms, especially irritabibity, anxiety, gastro-intestinal complaints, restless pes and headache. In 14 per cent. full-time empdop ment seemed to be prevented by illness. STxty per cent. of the men who had been ill at disch had improved by the time they appeared of or examination. Only 36 per cent. had sought Gan treatment for their symptoms. Some 40 per concts were drawing compensation for psychiatric ability, but in only ro per cent. of the entixe sample was such payment thought to have an effect.

Medical literature contains few such large-scale studies of neurosis, and very few so well doco mented as this. The authors are to be congratuse lated on the product of their prolonged aret diligent labour.

\section{MANAGEMENT OF LIFE-THREATENING POLIOMYELITIS}

Edited by H. C. A. Lassen, M.D. Pp. xix +179 , with 55 illustrations. Edinburgh: E. \& Livingstone Ltd. 1956. 22s. 6d.

This book contains a series of papers analysing the experiences gained in the $1952-53$ poliomyelits epidemic in Copenhagen. This epidemic was characterized by an unusually high percentage of patients suffering from bulbar paralysis and the manner in which Professor Lassen and his colleagues tackled this emergency was a remarkable achieve ment. This factor and the limited number of mechanical respirators available soon led them to treat almost all their patients who showed evidenee 